\title{
MEMBANGUN PENDIDIKAN KARAKTER MELALUI PEMBELAJARAN SAINS DI SEKOLAH DESA PERCUT SEI TUAN
}

\author{
Khairiah $^{1}$, Dahlia Sirait ${ }^{2}$ \\ Universitas Muslim Nusantara (UMN) Al-Washliyah \\ Jl. Garu II No. 93 Medan \\ Pendidikan Fisika ${ }^{1}$, Pendidikan Bahasa Inggris ${ }^{2}$
}

\begin{abstract}
Abstrak
Pembelajaran sains sebagai subsistem pendidikan nasional memberi kontribusi penting dalam pembentukan karakter siswa. Pembelajaran sains yang benar akan mengarahkan siswa untuk memiliki karakter-karakter diantaranya berupa kecermatan, disiplin, kejujuran, ketekunan, berpikir kritis, bertanggungjawab, dan saling bekerja sama. Desa Percut Sei Tuan salah satu desa di Kota Medan akan menjadi sasaran pengabdian masyarakat untuk melakukan pelatihan dan sosialisasi terkait Membangun Pendidikan Karakter Melalui Pembelajaran Sains di Sekolah Desa Percut Sei Tuan. Hal ini dilakukan karena permasalahan yang berkaitan dengan Narkoba di Desa ini agak mengkhawatirkan dan ini berkaitan dengan keluarga terdekat yang merupakan pemakai dan pengedar. Agar pendidikan karakter tidak bertambah merosot dan pengaruh narkoba tidak semakin menjadi-jadi, maka perlu adanya penyuluhan ke sekolah- sekolah khususnya sekolah. Metode yang digunakan pada pengabdian ini adalah pendekatan keterampilan proses melalui pelatihan dan sosialisasi. Pendekatan keterampilan proses adalah proses pembelajaran yang dirancang sedemikian rupa sehingga siswa dapat menemukan fakta fakta, membangun konsepkonsep dan teori teori dengan keterampilan intelektual dan sikap ilmiah siswa sendiri.
\end{abstract}

Kata Kunci : Pendidikan Karakter, Pembelajaran Sains, Pelatihan/Sosialisasi

\begin{abstract}
Learning science as a national education subsystem makes an important contribution in the formation of student character. Correct learning of science will lead the students to have the characters in the form of accuracy, discipline, honesty, perseverance, critical thinking, responsible, and work together. Desa Percut Sei Tuan, one of the villages in Medan City, will be the target of community service to conduct training and socialization related to Building Character Education through Science Learning at Perci Sei Tuan Village School. This is done because the problems associated with drugs in this village is somewhat alarming and this is related to the closest family who is a user and a distributor. In order for character education does not increase and decline drug influence is not increasingly become-so, it is necessary to counseling to schools, especially schools. The method used in this devotion is the process skill approach through training and socialization. A process skill approach is a learning process designed in such a way that students can discover facts, build concepts and theory theories with their own intellectual and scientific skills.
\end{abstract}

Keyword: Character Education, Science Lesson, Training/Socialization 


\section{PENDAHULUAN}

Dunia pendidikan dewasa ini dihadapkan pada tuntutan yang semakin berat, terutama untuk mempersiapkan peserta didik agar mampu menghadapi berbagai dinamika perubahan yang berkembang dengan sangat cepat khususnya pergeseran aspek nilai dan moral dalam kehidupan masyarakat. Badan Kependudukan dan Keluarga Berencana Nasional (BKKBN) melaporkan bahwa $51 \%$ remaja di Jabodetabek telah melakukan seks pranikah. Beberapa wilayah lain di Indonesia melaporkan bahwa seks pranikah juga dilakukan remaja, misalnya saja di Surabaya tercatat $54 \%$, di Bandung 47\%, dan di Medan 52\%. Data ini tidak jauh berbeda dengan data yang dilansir sebelumnya oleh Komnas Pelindungan Anak, PKBI, BKKBN pada tahun 2009 di mana $62,7 \%$ remaja mengaku pernah melakukan hubungan seks pranikah, $21,2 \%$ remaja pernah aborsi, 93,7\%, remaja SMP, SMA pernah melakukan ciuman serta oral seks, dan 97,0\% remaja SMP-SMA pernah menonton film porno (Indarini, 2010). Banyak orang berpandangan bahwa kondisi demikian diduga berawal dari apa yang dihasilkan oleh dunia pendidikan.

Sains sebenarnya dapat digunakan untuk mengembangkan kemampuan-kemampuan siswa baik aspek kognitif, aspek psikomotorik, maupun aspek afektif. Oleh karena itu, sains sebaiknya dipelajari dengan caracara sedemikian rupa sehingga memungkinkan bagi siswa untuk dapat menerapkan kemampuannya secara berkarakter dalam pemecahan masalahmasalah nyata yang dijumpai dalam kehidupannya sehari-hari. Namun pada kenyataannya, masih banyak kasuskasus yang mengindikasikan rendahnya karakter manusia Indonesia. Masih banyak perbedaan pendapat atau permasalahan diselesaikan oleh siswa atau masyarakat dengan cara tidak berkarakter. Mungkin saja hal ini menunjukkan bahwa pendidikan nasional telah gagal membentuk manusia Indonesia yang berkarakter. Jika benar, berarti amanat Undang-
Undang Dasar Negara Republik Indonesia Tahun 1945 dan UU RI No. 20 Tahun 2003tentangSistem Pendidikan Nasional, khususnya Pasal 3 yang menyebutkan bahwa Pendidikan Nasional berfungsi mengembangkan kemampuan dan membentuk watak serta peradaban bangsa yang bermartabat dalam rangka mencerdaskan kehidupan bangsa, bertujuan untuk berkembangnya potensi siswa agar menjadi manusia yang beriman dan bertakwa kepada Tuhan Yang Maha Esa, berakhlak mulia, sehat, berilmu, cakap, kreatif, mandiri, dan menjadi warga negara yang demokratis serta bertanggung jawab belum sepenuhnya terwujud.

Dunia pendidikan, sesungguhnya memberikan kontribusi paling besar terhadap situasi ini. Sains sebenarnya dapat digunakan untuk mengembangkan kemampuankemampuan siswa baik aspek kognitif, aspek psikomotorik, maupun aspek afektif. Oleh karena itu, sains sebaiknya dipelajari dengan cara- cara sedemikian rupa sehingga memungkinkan bagi siswa untuk dapat menerapkan kemampuannya secara berkarakter dalam pemecahan masalah- masalah nyata yang dijumpai dalam kehidupannya sehari-hari.

Berdasarkan uraian diatas Desa Percut Sei Tuan salah satu desa di Kota Medan akan menjadi sasaran pengabdian masyarakat untuk melakukan pelatihan dan sosialisasi terkait "Membangun Pendidikan Karakter Melalui Pembelajaran Sains di Sekolah Desa Percut Sei Tuan'”.

\section{METODE PELAKSANAAN}

Terkait dengan pendidikan karakter permasalahan yang sedang dihadapi mitra adalah:

1. Rendahnya pendidikan karakter di tingkat sekolah Desa Percut Sei Tuan

2. Maraknya isu Narkoba di kalangan keluarga terdekat yang berimbas pada siswa siswi sekolah Desa Percut Sei Tuan Agar pendidikan karakter tidak bertambah merosot 
dan pengaruh narkoba tidak semakin menjadi-jadi, maka perlu adanya penyuluhan ke sekolahsekolah khususnya sekolah. Dikarenakan pendidikan karakter lebih banyak dibutuhkan dan disupply dari tingkat dasar sampai Menengah dan seterusnya.

Metode yang digunakan pada pengabdian ini adalah pendekatan keterampilan proses melalui pelatihan dan sosialisasi. Pendekatan keterampilan proses adalah proses pembelajaran yang dirancang sedemikian rupa sehingga siswa dapat menemukan fakta fakta, membangun konsep-konsep dan teori teori dengan keterampilan intelektual dan sikap ilmiah siswa sendiri.

\section{Tabel 3.1. Rincian Rencana Kegiatan} Pengabdian

\begin{tabular}{|c|c|}
\hline Kegiatan & Deskripsi Kegiatan \\
\hline $\begin{array}{l}\text { Pelatihan } \\
\text { dan } \\
\text { Sosialisasi }\end{array}$ & $\begin{array}{l}\text { - Mempresentasikan } \\
\text { materi pendidikan } \\
\text { karakter melalui } \\
\text { keterampilan proses } \\
\text { berbasis } \\
\text { pembelajaran sains }\end{array}$ \\
\hline Diskusi & $\begin{array}{l}\text { Tanya jawab seputar } \\
\text { pendidikan karakter } \\
\text { melalui pembelajaran } \\
\text { sains }\end{array}$ \\
\hline
\end{tabular}

\section{HASIL}

Hasil dan luaran yang dihasilkan dari kegiatan ini secara umum adalah dapat membangun pendidikan karakter melalui pembelajaran sains dengan memunculkan sikap ilmiah. Secara khusus, target dan luaran kegiatan adalah sebagai berikut:

1. Dapat membebrikan masukan tentang strategi memasukkan nilai pendidikan karakter memlalui RPP di mapel Bilogi dan Fisika;
2. Dapat memberikan penguatan atau memberikan bekal tentang sikap ilmiah kepada siswa. Pembelajaran sains mengandung empat unsur yaitu sikap, proses, produk dan aplikasi, sehingga siswa diharapkan tidak hanya memiliki pengetahuan namun juga menguasai proses ilmiah dan dapat mengaplikasikan ilmu yang diperoleh;

3. Pembelajaran sains juga perlu memberikan penguatan pada karakter sumber daya manusia (SDM). Ciri-ciri karakter SDM yang kuat meliputi: (a) religius, yaitu memiliki sikap hidup dan kepribadian yang taat beribadah, jujur, terpercaya, dermawan, saling tolong menolong, dan toleran; (b) moderat, yaitu memiliki sikap hidup yang tidak radikal dan tercermin dalam kepribadian yang tengahan antara individu dan sosial, berorientasi materi dan ruhani serta mampu hidup dan kerjasama dalam kemajemukan; (c) cerdas, yaitu memiliki sikap hidup dan kepribadian yang rasional, cinta ilmu, terbuka, dan berpikiran maju; dan (d) mandiri, yaitu memiliki sikap hidup dan kepribadian merdeka, disiplin tinggi, hemat, menghargai waktu, ulet, wirausaha, kerja keras, dan memiliki cinta kebangsaan yang tinggi tanpa kehilangan orientasi nilai-nilai kemanusiaan universal dan hubungan antarperadaban bangsa bangsa;

4. Peningkatan pemahaman dan ketrampilan guru guru dalam menyusun pembelajaran sains berbasis pendidikan karakter;

5. Dapat mempublikasikan hasil dari kegiatan dalam Jurnal ber ISSN.

\section{KESIMPULAN}

Kesimpulan dari kegiatan pengabdian di sekolah Desa Percut Sei Tuan ini adalah guru-guru di sekolah lebih terbuka dan mau diajak sharing mengenai pengalaman guru-guru di lapangan, menghadapi siswa-siswai 
secara langsung dengan berbagai masalah yang dihadapi. Peningkatan pemahaman dan keterampilan dapat terlihat dari pertanyaan pertanyaan yang lugas yang sesuai dengan tema membangun karakter siswa untuk keberlangsungan bangsa. Guru -guru di sekolah tersbut mudah diajak kerja sama sehingga hal-hal yang ingin disampaikan sesuai target. Metode sosilisasi seperti ini cukup baik digunakan untuk membuaka keterbukaan guru-guru dalam menghadapi berbagai masalah di sekolah.

\section{DAFTAR PUSTAKA}

Dwikoranto. 2010. Membangun Karakter Melalui Pembelajaran Berbasis Nilai di Fullday School. Proseding Seminar Nasional Pendidikan IPA Tahun 2010 dengan tema Membangun Profesionalisme Guru IPA melalui Penyelenggaraan Pendidikan Profesi Guru (PPG). FMIPA Universitas Negeri Yogyakarta

Juniarso, T. 2010. Pendidikan Karakter di Sekolah (Character Education In School) Sebuah Usulan Gagasan: Pengembangan Model Kontrak Belajar dengan Pelibatan Masyarakat Untuk Penguatan Karakter Siswa Dalam Pembelajaran Sains. Surabaya: Universitas PGRI Adi Buana

Kompas. 2010. Pengguna Narkoba Mencapai 3,6 Juta Orang. Edisi Senin, 26 April 2010.

Koesoema, A. D. 2007. Pendidikan Karakter: Strategi Mendidik Anak di Zaman Global. Jakarta: PT. Gramedia Widiasarana Indonesia

Malik, A. 2007. 45\% Remaja Lakukan

Free Sex. Harian Seputar Indonesia Edisi 21 Mei 2007

Sirajuddin, N. 2010. Mereorientasi Pendidikan Karakter Indonesia. Harian Fajar M 